\title{
Matéria orgânica e infiltração da água em solo sob consórcio milho e forrageiras
}

\author{
Juliana H. Sato ${ }^{1}$, Cícero C. de Figueiredo ${ }^{2}$, Tairone P. Leão ${ }^{2}$, \\ Maria L. G. Ramos \& Eiyti Kato 2
}

\begin{abstract}
RESU M O
A infiltração é o processo pelo qual a água penetra no solo através de sua superfície e sua dinâmica pode ser condicionada por diversos fatores, dentre eles os sistemas de manejo do solo adotados. 0 objetivo deste trabalho foi estimar a velocidade de infiltração da água e os teores de matéria orgânica do solo em sistema de consórcio milho e forrageiras. 0 experimento foi realizado em delineamento de blocos casualizados, com três repetições. Foram estudados os efeitos de cinco tratamentos submetidos ao manejo de plantio direto: 1) M ilho Solteiro (Zea mays L.); 2) Braquiária H umidícola (Brachiaria humidicola); 3) Consórcio Milho e Braquiária Humidícola; 4) Capim Aruana (Panicum maximum cv. Aruana); 5) Consórcio Milho e Capim Aruana. Utilizou-se, para determinação da velocidade de infiltração básica (VIB), o método dos infiltrômetros de cilindros concêntricos. O utros atributos físicos do solo e a matéria orgânica do solo foram avaliados buscando-se associá-los aos valores de VIB encontrados. O s resultados revelaram que sob plantio direto os sistemas apresentaram elevados valores de VIB. 0 sistema Milho Solteiro apresentou a maior VIB e a inserção de forrageiras nos sistemas provocou redução da VIB; todos os sistemas apresentaram diminuição dos teores de matéria orgânica em profundidade.
\end{abstract}

Palavras-chave : infiltrômetro, plantio direto, água no solo

\section{Soil organic matter and water infiltration under maize and forage intercropping}

\begin{abstract}
Infiltration is a process by which water penetrates through the soil by its surface, and its dynamics can be influenced by several factors, among them, the soil management system adopted. The objective of this work was to estimate water infiltration rate and soil organic matter content in maize and forage intercropping systems. The experiment was conducted in a randomized block design with three replications. Five treatments under no-tillage management were evaluated: 1) Corn (Zea mays L.), 2) brachiaria humidicola (Brachiaria humidicola), 3) Corn and brachiaria humidicola intercropping, 4) Aruana grass (Panicum maximum cv. Aruana), 5) Corn and Aruana grass intercropping. The double ring infiltrometer method was used to determine the basic infiltration rate (VIB). Soil physical properties and soil organic matter were evaluated and correlated with VIB values. Results revealed high VIB values for no-tillage. The highest VIB values were observed in the corn treatment. VIB values decreased with the inclusion of forages. All cultivation systems showed a decrease of organic matter with depth.
\end{abstract}

Key words: infiltrometer, no-tillage, soil water

\footnotetext{
${ }^{1}$ M estranda do Curso de Pós-Graduação em A gronomia da U niversidade de Brasília, CEP 70910-9000, Brasília, DF. E-mail: jh.sato@yahoo.com.br 2 Faculdade de Agronomia e Medicina Veterinária da Universidade de Brasília, Campus U niversitário Darcy Ribeiro, Asa N orte, CEP 70910-900, Brasília, DF. E-mails: cicerocf@unb.br; trpleao@hotmail.com; lucrecia@unb.br; kato@unb.br
} 


\section{INTRODUÇÃO}

A dinâmica da água no solo está diretamente relacionada à produção vegetal e o seu conhecimento é de interesse fundamental para a tomada de decisão sobre a exploração agrícola (Calheiros et al., 2009). A obtenção da taxa de infiltração de água no solo é de grande importância para definir técnicas de conservação, planejamento de projetos de irrigação e sistemas de drenagem (Paixão et al., 2005).

A infiltração é o processo pelo qual a água penetra no solo através de sua superfície (Brandão et al., 2009). É considerado um dos mais importantes processos que compõem o ciclo hidrológico, determinante para disponibilizar água para as culturas, na recarga dos lençóis freáticos, no escoamento superficial e no manejo do solo e água (Cecílio et al., 2003).

Com o tempo, o solo cultivado com preparo mecânico tende a ter sua estrutura alterada pelo fracionamento dos agregados, com redução do volume de macroporos e promove o aumento da densidade do solo (Panachuki et al., 2006). Desta forma ocorrem diminuição da taxa de infiltração de água no solo e, consequentemente, aumento no escoamento superficial.

O preparo convencional altera as condições físicas do solo por desagregação e compactação das camadas superficiais, diminuindo a infiltração de água e facilitando o processo erosivo. Os sistemas conservacionistas de uso do solo, como o plantio direto, surgiram para diminuir os efeitos prejudiciais dos implementos no preparo do solo; sobretudo em condições tropicais, esses sistemas minimizam sua mobilização e mantêm maior proteção da superfície com os resíduos culturais (Souza \& Alves, 2003).

O plantio direto é um sistema conservacionista que apresenta boa capacidade de proteção do solo. Além disso, há o aumento da possibilidade da infiltração da água devido à maior rugosidade da superfície (Llanillo et al., 2006). Mesmo sob plantio direto o solo pode reduzir a capacidade de infiltração de água, em virtude do adensamento de partículas e da maior densidade do solo nas camadas superficiais (Pinheiro et al., 2009).

Segundo Moraes (1993), a decomposição das raízes das plantas forma canalículos no solo, aumentando a infiltração de água, melhorando sua estrutura pela adição de matéria orgânica, elevando a capacidade de retenção de água e redução da velocidade de escoamento da enxurrada. No entanto, pastagens nativas perenes apresentaram baixa capacidade de infiltração de água no solo (Pinheiro et al., 2009).

O sistema de Integração Lavoura-Pecuária (ILP) é outro tipo de manejo do solo que, aliado a práticas conservacionistas, como plantio direto, pode ser considerado uma alternativa econômica e sustentável. O sistema de ILP possibilita uma exploração mais sustentável do módulo produtivo pois, além de proteger o solo, melhora sua qualidade (Souza \& Teixeira, 2007).

No Brasil, o consórcio de milho com espécies forrageiras vem crescendo como uma das modalidades da ILP. Nas suas diversas possibilidades este sistema de manejo tem, como um dos princípios, a conservação do solo e da água, fato que implica na necessidade de se entender as alterações nas dinâmicas da água no solo quando se utilizam diferentes espécies forrageiras em consórcio com o milho.
O objetivo deste trabalho foi determinar a velocidade de infiltração de água no solo e sua relação com propriedades físicas e a matéria orgânica do solo, em sistemas de consórcio milho e forrageiras sob plantio direto.

\section{Material E MÉTODOS}

O trabalho foi conduzido no campo experimental da Fazenda Água Limpa, da Universidade de Brasília, localizada em Vargem Bonita, Brasília, DF (15 55' 58' S e 47 51' 02' 'W e altitude de $1000 \mathrm{~m}$ ). Os sistemas de manejo foram instalados em um Latossolo Vermelho-Amarelo distrófico típico, na safra 2007/ 2008.

Anterior ao início do experimento, a área era cultivada com capim andropogon (Andropogon gayanus) durante seis anos e apresentava homogeneidade de cobertura vegetal; em 2007 realizou-se aração seguida de gradagem em toda a área; em seguida, realizou-se a calagem com aplicação de $2,6 \mathrm{Mg} \mathrm{ha}^{-1} \mathrm{de}$ calcário dolomítico.

O experimento foi montado utilizando-se o delineamento de blocos ao acaso, com três repetições e cinco tratamentos. A área de cada parcela é de $80 \mathrm{~m}^{2}$ e os tratamentos estudados foram: 1) M: milho solteiro (Zea mays, híbrido BR 2020); 2) MA: milho consorciado com capim aruana (Panicum maximum cv. Aruana); 3) MH: milho consorciado com braquiária humidícola (Brachiaria humidicola); 4) A: capim aruana; 5) BH: braquiária humidícola.

As medições da velocidade de infiltração de água no solo foram realizadas durante o mês de abril de 2010, com ausência total de chuvas na área experimental, durante as avaliações.

O método de campo utilizado na determinação da taxa de infiltração foi o infiltrômetro de cilindros concêntricos, conforme Bernardo et al. (2005), que consiste de dois cilindros com $30 \mathrm{~cm}$ de altura; um deles possui diâmetro de $40 \mathrm{~cm}$ e o outro de 15 $\mathrm{cm}$.

Quando a taxa de infiltração se apresentou constante com no mínimo três medidas iguais, suspendeu-se o processo considerando-se que no momento se havia atingido a velocidade de infiltração básica (VIB) ou taxa de infiltração constante. O tempo para obtenção da VIB variou de 70 a 110 min; em cada parcela foram feitas duas repetições para determinação da velocidade de infiltração, totalizando trinta medições.

Com os resultados da lâmina de água acumulada no solo (I), em função do tempo de infiltração $(\mathrm{t})$ obtiveram-se, por regressão, os parâmetros ( $\mathrm{k}$ e $\mathrm{n}$ ) da equação de Kostiakov $\left(\mathrm{I}=\mathrm{k} \cdot \mathrm{t}^{\mathrm{n}}\right)$ e a velocidade de infiltração da água no solo $\left(\mathrm{VI}=\mathrm{knt}^{\mathrm{n}-1}\right)$ foi obtida derivando-se a equação da lâmina acumulada em relação ao tempo $(\mathrm{VI}=\mathrm{dI} / \mathrm{dt})$.

Em cada parcela foram coletadas, aleatoriamente, cinco subamostras deformadas, formando uma amostra composta; a coleta foi realizada em dezembro de 2009 , antes do plantio, em quatro camadas: 0-5; 5-10; 10-20 e 20-30 cm enquanto amostras indeformadas foram coletadas na mesma época e nas mesmas camadas para a determinação da densidade de solo, utilizandose anéis de aço de $100 \mathrm{~cm}^{3}$ de volume. 
Com vista à determinação dos atributos físicos (densidade de partículas, densidade do solo e porosidade total) e, na determinação da matéria orgânica do solo, o método por oxidação via úmida com dicromato de potássio, na presença de ácido sulfúrico, sem aquecimento externo, utilizou-se as metodologias descritas em EMBRAPA (1997).

Os dados foram submetidos à análise de variância (ANOVA). Para as variáveis medidas em profundidade, considerou-se a profundidade como medida repetida, conforme Coulter et al. (2009). Os dados relacionados à velocidade de infiltração foram ajustados a um modelo utilizando-se regressão não-linear. Os parâmetros obtidos pelo ajuste foram submetidos à ANOVA para comparação entre tratamentos. As médias foram comparadas pelo teste de Tukey a 5\% de significância, enquanto as análises foram realizadas através do programa estatístico SAS (SAS, 1991).

\section{RESULTADOS E DisCUSSÃO}

Na Tabela 1 são apresentadas as significâncias dos valores de F para as fontes de variação usadas nas análises estatísticas. Constata-se que não houve efeito significativo de tratamento nem de profundidade nos atributos físicos do solo (densidade do solo - DS; densidade de partículas - DP e porosidade total - PT). Só foi significativo o efeito de profundidade nos teores de matéria orgânica total do solo.

Tabela 1. Resumo da análise de variância e níveis de significância para os parâmetros matéria orgânica total (MOS), densidade do solo (DS), D ensidade de partículas (DP) e Porosidade total (PT)

\begin{tabular}{crcccc}
\hline Fonte de & \multicolumn{5}{c}{ Quadrado médio } \\
\cline { 2 - 6 } variação & GL & MOS & DS & DP & PT \\
Trat & 4 & $0,0656 \mathrm{~ns}$ & $0,0001 \mathrm{~ns}$ & $0,0097 \mathrm{~ns}$ & $0,0010 \mathrm{~ns}$ \\
Prof & 3 & $3,1460 * * *$ & $0,0035 \mathrm{~ns}$ & $0,0338 \mathrm{~ns}$ & $0,0003 \mathrm{~ns}$ \\
Trat x Prof & 12 & $0,0340 \mathrm{~ns}$ & $0,0063 \mathrm{~ns}$ & $0,0192 \mathrm{~ns}$ & $0,0017 \mathrm{~ns}$ \\
\hline **** significativo a $1 \%$ de probabilidade; ns - não signific ativo a $5 \%$ de probabilidade pelo teste F
\end{tabular}

Apesar da ausência de diferenças entre os sistemas de manejo nos atributos físicos do solo, são comuns, na literatura, trabalhos que apresentam valores distintos entre esses atributos. Sales et al. (1999) verificaram uma relação inversa entre os atributos de densidade do solo e porosidade total e entre densidade do solo e velocidade de infiltração básica de água no solo. Pott \& De Maria (2003) verificaram que em diferentes solos estudados sob sistema de plantio direto a densidade do solo diminuiu e a porosidade total aumentou com o aumento da profundidade do solo. Figueirêdo et al. (2009) notaram diferenças entre sistemas sob integração lavoura-pecuária quanto à densidade do solo e porosidade total e ausência de diferença em relação aos valores de densidade de partículas. Ainda de acordo com Figueirêdo et al. (2009), as maiores diferenças são verificadas quando os sistemas de preparo convencional e conservacionistas são confrontados. Como o presente estudo foi realizado em áreas sob plantio direto implantado há três anos, a ação das raízes ainda não foi suficiente para alterar os atributos físicos estudados.

Os valores médios observados de velocidade de infiltração básica, em $\mathrm{cm} \mathrm{h}^{-1}$, para os sistemas de cultivo foram: $\mathrm{M}=41,97$; $\mathrm{MH}=31,73 ; \mathrm{MA}=26,13 ; \mathrm{A}=21,90$ e $\mathrm{BH}=13,83$.

Todos os sistemas apresentaram valores de velocidade de infiltração básica (VIB) considerados muito altos, de acordo com classificação de Bernardo et al. (2005). Os valores da VIB variaram de 13,83 a $41,97 \mathrm{~cm} \mathrm{~h}^{-1}$ e estão dentro da faixa dos resultados encontrados por outros autores em solos sob diferentes sistemas de manejo (Souza \& Alves, 2003; Cunha et al., 2009; Fontenele et al., 2009; Prando et al., 2010).

O sistema $\mathrm{M}$ apresentou o maior valor de velocidade de infiltração básica (VIB) de água no solo $(\mathrm{P}<0,05)$. A introdução de forrageiras em consórcio promoveu diminuição dos valores de VIB, com menores valores em relação ao milho solteiro. Não foram observadas diferenças entre os consórcios (MB e MA) nem entre os sistemas, somente com forrageiras (BHe A).

Esses resultados demonstram que a consorciação do milho com braquiária humidícola promoveu aumento da VIB, quando comparado com a braquiária solteira. Pinheiro et al. (2009) também verificaram maiores capacidades de infiltração em solos cultivados com milho sob plantio direto e convencional, quando comparados com aqueles sob pastagens nativas.

De acordo com os resultados dos atributos físicos do solo (Tabela 1), sugere-se que a velocidade de infiltração básica pode estar relacionada ao sistema radicular das plantas, já que os sistemas não diferiram quanto aos atributos físicos estudados (densidade do solo, densidade de partículas e porosidade total). Pinheiro et al. (2009) também inferiram que as raízes das gramíneas forrageiras dificultam o movimento vertical da água na camada superficial do solo, reduzindo significativamente a capacidade de infiltração.

As raízes de braquiária humidícola apresentam comportamento de crescimento mais lateral do que em profundidade, formando canalículos horizontais, o que pode provocar a diminuição da velocidade de infiltração (Costa et al., 2002). Estudos mostram que 70 a $80 \%$ das raízes da braquiária humídicolas se situam nos primeiros $20 \mathrm{~cm}$ do solo (Brasil et al., 2002; Costa et al., 2002) e, deste total, 80\% da densidade radicular média são representados por raízes finas (Costa et al., 2002). Coelho \& Pereira (2006) afirmaram que as raízes finas e superficiais impedem a infiltração e a desagregam o solo, alterando a velocidade de infiltração de água. Sugere-se, portanto, que os menores valores de VIB em sistemas com forrageiras podem ser relacionados à quantidade e distribuição de raízes finas necessitando, entretanto, ser estudado de forma mais profunda.

Na Tabela 2 são apresentados os valores das constantes de proporcionalidade (parâmetros da equação) que compõem o modelo que descreve a velocidade ou taxa de infiltração em função do tempo. O parâmetro k se aproxima da velocidade de infiltração inicial.

Os valores de k seguiram a mesma tendência da VIB entre os sistemas estudados. Verifica-se que o sistema $\mathrm{M}$ apresentou maior valor de $\mathrm{k}$ que os sistemas com capim aruana (solteiro ou consorciado). Esses resultados reforçam as maiores taxas de infiltração proporcionadas pelo milho solteiro. Prando et al. 
Tabela 2. Parâmetros k e n (média \pm desvio padrão) da equação que descreve a velocidade de infiltração instantânea $\left(\mathrm{VI}=\mathrm{k} \mathrm{n} \mathrm{T}^{\mathrm{n}-1}\right)$ para os sistemas de manejo estudados

\begin{tabular}{ccc}
\hline \multirow{2}{*}{ Sistema } & \multicolumn{2}{c}{ Parâmetro } \\
\cline { 2 - 3 } & $\mathbf{k}$ & $\mathbf{n}$ \\
M & $75,04 \pm 20,71 \mathrm{a}$ & $0,88 \pm 0,04 \mathrm{a}$ \\
$\mathrm{BH}$ & $26,65 \pm 11,10 \mathrm{c}$ & $0,82 \pm 0,07 \mathrm{a}$ \\
MH & $53,74 \pm 13,79 \mathrm{ab}$ & $0,86 \pm 0,03 \mathrm{a}$ \\
$\mathrm{A}$ & $44,33 \pm 6,57 \mathrm{bc}$ & $0,84 \pm 0,06 \mathrm{a}$ \\
MA & $41,87 \pm 2,65 \mathrm{bc}$ & $0,87 \pm 0,03 \mathrm{a}$ \\
\hline
\end{tabular}

M - Milho solteiro; BH - braquiária humidícula; MBH - Milho + braquiária humidícula; A - Capim Aruana; MA - Milho + Capim Aruana. Médias seguidas da mesma letra na coluna não diferem entre si pelo teste de Tukey a $5 \%$ de probabilidade

(2010) encontraram diferenças entre as velocidades iniciais e estáveis (VIB) em sistemas sob plantio direto com diferentes culturas. No estudo desses autores, os sistemas com braquiária ruziziense na rotação apresentaram menores valores de velocidade de infiltração inicial e estável na superfície do solo e maiores valores nas profundidades 10 e $20 \mathrm{~cm}$, quando comparados com rotações só com culturas graníferas.

A diferença entre o comportamento da infiltração de água no solo entre os diferentes sistemas de produção pode estar associada ao sistema radicular das forrageiras, que altera o comportamento hidrodinâmico devido, provavelmente, ao crescimento e distribuição das raízes no solo.

Na Tabela 3 são apresentados os teores de matéria orgânica do solo (MOS) dos sistemas de produção em cinco camadas de solo.

Tabela 3. Matéria orgânica total do solo $\left(\mathrm{g} \mathrm{kg}^{-1}\right)$ em sistemas de manejo em diferentes camadas do solo

\begin{tabular}{cccccc}
\hline Camadas & \multicolumn{5}{c}{ Sistema de manejo } \\
\cline { 2 - 6 } (cm) & $\mathbf{M}$ & BH & MH & A & MA \\
0 a 5 & 38,2 a & $35,2 \mathrm{a}$ & $37,5 \mathrm{a}$ & $37,7 \mathrm{a}$ & $37,3 \mathrm{a}$ \\
5 a 10 & $39,5 \mathrm{a}$ & $35,9 \mathrm{a}$ & $35,4 \mathrm{a}$ & $35,3 \mathrm{a}$ & $35,7 \mathrm{a}$ \\
10 a 20 & $33,0 \mathrm{~b}$ & $32,8 \mathrm{a}$ & $31,5 \mathrm{~b}$ & $33,1 \mathrm{ab}$ & $31,5 \mathrm{ab}$ \\
20 a 30 & $26,9 \mathrm{C}$ & $26,6 \mathrm{~b}$ & $27,3 \mathrm{c}$ & $28,3 \mathrm{~b}$ & $26,6 \mathrm{~b}$ \\
\hline
\end{tabular}

M - Milho solteiro; BH - braquiária humidícula; MBH - Milho + braquiária humidícula; A - Capim Aruana; MA - Milho + Capim Aruana. Médias seguidas da mesma letra na coluna não diferem pelo teste de Tukey a nível de $5 \%$ de probabilidade

Como não foram significativos os efeitos de tratamento quanto aos teores de matéria orgânica do solo (Tabela 1), serão discutidas apenas as diferenças entre profundidades dentro de cada sistema. Verifica-se tendência de redução dos teores de matéria orgânica com o aumento da profundidade do solo, fato esperado em sistemas de manejo conservacionistas como o plantio direto, conforme verificado em diversos trabalhos (Perez et al., 2004; Sá \& Lal, 2009; Fontenele et al., 2009; Figueirêdo et al., 2010).

De acordo com Lopes et al. (2004), no plantio direto a ausência de preparo do solo e a quantidade e qualidade, tanto dos resíduos das culturas de interesse econômico como das plantas de cobertura ao longo dos anos, acarretam um aumento gradual no teor de matéria orgânica, principalmente na camada superficial $(0 \mathrm{a} 10 \mathrm{~cm})$. Este aumento depende de diversos fatores, como quantidade e qualidade dos resíduos das culturas utilizadas, tanto quanto do tempo de implantação do plantio direto (Sá \& Lal, 2009).
A intensidade com que esta redução dos teores de MOS ocorreu, variou conforme o sistema de culturas utilizado. $\mathrm{Na}$ comparação dos teores de MOS entre as camadas de solo observou-se, em cada sistema de produção, que nos sistemas com braquiária humidícola $(\mathrm{BH}$ e $\mathrm{MH})$ houve diferenças significativas nas camadas de 20 a $30 \mathrm{~cm}$ em relação às demais camadas. Nos demais sistemas (M, A e MA) também houve diferenças significativas entre as camadas de solo para cada sistema, mas se observa que essas diferenças são menos estratificadas quando comparadas aos sistemas que envolvem a braquiária humidícola.

Segundo Dias Filho (2005), as pastagens contribuem para o aumento dos teores de matéria orgânica do solo devido ao seu sistema radicular, que se distribui pelas camadas de solo exploradas pelas raízes que serão decompostas com o tempo.

No presente estudo o pouco tempo de implantação do plantio direto e a presença de pastagens em toda a área antes da implantação do experimento, podem explicar a ausência de diferenças nos teores de MOS entre os sistemas estudados.

A matéria orgânica apresenta importância na estrutura dos solos, com influência na velocidade de infiltração de água no solo (Brandão et al., 2009). Entretanto, os valores de VIB encontrados neste estudo não podem ser associados aos teores de matéria orgânica obtidos por não apresentarem diferenças significativas entre os sistemas estudados. Outros mecanismos, como o tamanho, densidade e distribuição das raízes, podem interferir na dinâmica de infiltração de água no solo, além da retenção de água no solo promovida pela ação dos diferentes sistemas radiculares.

\section{CONCLUSÕES}

1. Os sistemas estudados apresentaram diferentes velocidades de infiltração básica (VIB), sendo que o sistema milho solteiro apresentou a maior VIB, os consórcios valores intermediários e os sistemas somente com forrageiras, os menores valores.

2. Sob plantio direto a inserção de forrageira em um sistema influencia a velocidade de infiltração de água no solo.

\section{LITERATURA CITADA}

Bernardo, S.; Soares, A. A.; Mantovani, E. C. Manual de irrigação. 7.ed. Viçosa: UFV, 2005. 611p.

Brandão, V. S.; Pruski, F. P.; Silva, D. D. Infiltração da água no solo. 3.ed. Viçosa: UFV, 2009. 120p.

Brasil, F. C.; Rossiello, R. O. P.; Paciornik, S.; Abreu, J. B. R. Distribuição vertical de características morfológicas do sistema radicular de Brachiaria humidicola. Pasturas Tropicales, v.24, p.14-20, 2002.

Calheiros, C. B. M.; Tenório, F. J. C.; Cunha, J. L. X. L.; Silva, E. T.; Silva, D. F.; Silva, J. A. C. Definição da taxa de infiltração para dimensionamento de sistemas de irrigação por aspersão. Revista Brasileira Engenharia Agrícola e Ambiental, v.13, p.665-670, 2009. 
Cecílio, R. A.; Silva, D. D.; Pruski, F. F.; Martinez, M. A. Modelagem da infiltração de água no solo sob condições de estratificação utilizando-se a equação de Green-Ampt. Revista Brasileira Engenharia Agrícola e Ambiental, v.7, p.415-422, 2003.

Coelho, A. T.; Pereira, A. R. Efeitos da vegetação na estabilidade de taludes e encostas. Boletim Técnico, v.1, p.1-20, 2006.

Costa, F.; Pereyra, R. O.; Pacionirck, S.;Abreu, J. B. R. Distribuição vertical de características morfológicas do sistema radicular de Brachiaria humidicola. Pasturas Tropicales, v.24, p.14-20, 2002.

Coulter, J. A.; Nafziger, E. D.; Wander, M. Soil organic matter response to cropping system and nitrogen fertilization. Agronomy Journal, v.101, p.592-599, 2009.

Cunha, J. L. X. L.; Albuquerque, A. W.; Silva, C. A.; Araújo, E.; Santos Junior, R. B. Velocidade de infiltração em um Latossolo Amarelo submetido ao sistema de manejo plantio direto. Revista Caatinga, v.22, p.199-205, 2009.

Dias Filho, M. B. Degradação de pastagens - processos, causas e estratégias de recuperação. 2.ed. Belém: Embrapa Amazônia Oriental, 2005. 173p.

EMBRAPA - Empresa Brasileira de Pesquisa Agropecuária. Centro Nacional de Pesquisa de Solos. Manual de métodos de análise de solos. 2.ed. Rio de Janeiro: EMBRAPA, 1997. $212 \mathrm{p}$.

Figueirêdo, C. C.; Ramos, M. L. G.; Tostes, R. Propriedades físico-hídricas em Latossolo do Cerrado sob diferentes sistemas de manejo. Revista Brasileira de Engenharia Agrícola e Ambiental, v.13, p.146-151, 2009.

Figueiredo, C. C.; Resck, D. V. S.; Carneiro, M. A. C. Labile and stable fractions of soil organic matter under management systems and native Cerrado. Revista Brasileira de Ciência do Solo, v.34, p.907-916, 2010.

Fontenele, W.; Salviano, A. A. C.; Mousinho, F. E. P. Atributos físicos de um Latossolo Amarelo sob sistemas de manejo no cerrado piauiense. Revista Ciência Agronômica, v.40, p.194-202, 2009.

Llanillo, R. F.; Richart, A.; Tavares Filho, J.; Guimarães, M. F.; Ferreira, R. R. M. Evolução de propriedades físicas do solo em função dos sistemas de manejo em culturas anuais. Semina: Ciências Agrárias, v.27, p.205-220, 2006.

Lopes, A. S.; Wiethölter, S.; Guilherme, L. R. G.; Silva, C. A. Sistema de plantio direto: bases para o manejo da fertilidade do solo. São Paulo: ANDA. 2004. 115p.
Moraes, A. Pastagens como fator de recuperação de áreas degradadas In: Simpósio Sobre Ecossistemas de Pastagens, 2, Jaboticabal. Anais... Jaboticabal: UNESP, 1993. p.191-215.

Paixão, F. J. R.; Andrade, A. R. S. de; Azevedo, C. A. V. de; Silva, J. M.; Feitosa, R. M. Estimativa da infiltração da água no solo através de métodos empíricos e funções não-lineares. Revista Biológica de Ciência da Terra, v.5, p. 50-60, 2005.

Panachuki, E.; Alves Sobrinho, T.; Vitorino, A. C. T.; Carvalho, D. F.; Urchei, M. A. Avaliação da infiltração de água no solo, em sistema de integração agricultura-pecuária, com uso de infiltrômetro de aspersão portátil. Acta Scientiarum. Agronomy, v.28, p.129-137, 2006.

Perez, K. S. S., Ramos, M. L. G.; McManus, C. Carbono da biomassa microbiana em solo cultivado com soja sob diferentes sistemas de manejo nos cerrados. Pesquisa Agropecuária Brasileira, v.39, p.567-573, 2004.

Pinheiro, A.; Teixeira, L. P.; Kaufmann, V. Capacidade de infiltração de água em solos sob diferentes usos e práticas de manejo agrícola. Revista Ambiente e Água, v.4, p. 188199, 2009.

Pott, C. A.; De Maria, I. C.. Comparação de métodos de campo para determinação da velocidade de infiltração básica. Revista Brasileira de Ciência do Solo, v.27, p.19-27, 2003.

Prando, M. B.; Olibone, D.; Olibone, A. P. E.; Rosolem, C. A. Infiltração de água no solo sob escarificação e rotação de culturas. Revista Brasileira de Ciência do Solo, v.34, p. 693$700,2010$.

Sá, J. C. M.; Lal, R. Stratification ratio of soil organic matter pools as an indicator of carbon sequestration in a tillage chronosequence on a Brazilian Oxisol. Soil and Tillage Research, v.103, p.46-56, 2009.

Sales, L. E. de O.; Ferreira, M. M.; Oliveira, M. S.; Curi, N. Estimativa da velocidade de infiltração básica no solo. Pesquisa Agropecuária Brasileira, v.34, p. 2091-2095, 1999.

SAS - Statical Analysis System Institute. Procedure guide for personal computers. 5.ed. Cary: SAS Institute, 1991. 1104 p.

Souza, J. A.; Teixeira, M. R. Experiências com a implantação do sistema de integração lavoura-pecuária. Informe Agropecuário, v.28, p.112-119, 2007.

Souza, Z. M.; Alves, M. C. Movimento de água e resistência à penetração em um Latossolo Vermelho distrófico de Cerrado, sob diferentes usos e manejos. Revista Brasileira de Engenharia Agrícola e Ambiental, v.7, p.18-23, 2003. 